\title{
Screening for psychosocial factors in patients with irritable bowel syndrome
}

Kelsey T. Laird', Jeffrey M. Lackner²

${ }^{1}$ Department of Psychiatry and Biobehavioral Sciences, Semel Institute for Neuroscience and Human Behavior, David Geffen School of Medicine at UCLA, Los Angeles, CA, USA, ${ }^{2}$ Department of Medicine, University at Buffalo, SUNY, Buffalo, NY, USA

\section{RESUMEN}

Los factores psicosociales desempeñan un papel prominente tanto en el inicio como en la expresión de los síntomas del síndrome del intestino irritable (SII), particularmente entre los individuos que consultan a los gastroenterólogos. Aunque muchos pacientes con SII responden al tratamiento médico o dietético convencional, los resultados son menos positivos en los pacientes con síntomas gastrointestinales severos y/o problemas psicosociales significativos. El cribado sistemático de los pacientes con SII que asisten a una clínica ambulatoria gastrointestinal puede ser útil para identificar a las personas que tienen menos probabilidades de responder a la terapia convencional. En este artículo se plantean recomendaciones prácticas para los procedimientos de cribado y referencias a profesionales de la salud mental. (NeuroGastroLatam Rev. 2017;1: 144-155)

Corresponding author: Kelsey T. Laird, kelsey.laird@gmail.com

Palabras clave: Factores psicosociales. Asistencia al riesgo. Ansiedad. Depresión. Calidad de vida relacionada con la salud. 


\section{ABSTRACT}

Psychosocial factors play a prominent role in both the onset and expression of irritable bowel syndrome (IBS) symptoms - particularly among those individuals who consult gastroenterologists. Although many patients with IBS respond to conventional medical or dietary treatment, outcomes are less positive for patients with severe gastrointestinal (GI) symptoms and/or significant psychosocial problems. Routine screening of IBS patients attending a GI outpatient clinic can be helpful for identifying those individuals who are less likely to respond to conventional therapy. Practical recommendations for screening procedures and referrals to mental health professionals are discussed.

Key words: Psychosocial factors. Risk assessment. Anxiety. Depression. Health-related quality of life.

\section{INTRODUCTION}

Irritable bowel syndrome (IBS) is a painful and often debilitating functional gastrointestinal disorder (FGID) with a worldwide prevalence of approximately $11 \% 1$. IBS imposes significant personal and economic costs, which manifests in both lost productivity and high rates of healthcare utilization ${ }^{2,3}$. Although IBS is a benign medical disorder, the quality of life (QOL) of patients is similar to that of patients with life-threatening medical diseases $^{4,5}$.

Lacking a reliable biomarker, IBS is best understood from a biopsychosocial perspective $^{6}$. Whereas biomedical models explain symptoms solely in terms of physical pathology, the biopsychosocial model holds that biological processes (e.g., genetic predisposition and GI physiology), developmental factors (e.g., early life experiences), social environment (e.g., reinforcement contingencies and stress), cognitive processes (e.g., patient beliefs about their symptoms), and behavior (e.g., maladaptive coping) interact to facilitate and maintain IBS symptoms ${ }^{7}$. There are ät least four pathways by which psychosocial factors impact IBS. First, psychosocial factors such as trauma increase risk for the development of IBS $^{8}$. Compared to healthy controls, IBS patients are more likely to report a hiš̀tory of physical or sexutal abuse9. Further more, among individuals with IBS, abuse history is related to greater GI symptom sĕ verity, psychological distress, and life interference $^{10-13}$.

Second, stress affects central nervous system. processes that mediate gut sensation and function. Although stress also affects gư function in healthy individuals, patients with IBS demonstrate greater stress sensitivity with regard to gut motility, visceral perception, and hypothalamic-pituitary-adrenal axis hormone levels ${ }^{14}$. One central process is GI symptom-specific anxiety, which is regarded as a prominent endogenous stressor that can 
perpetuate IBS symptoms even in the absence of external stress ${ }^{15}$.

A third pathway by which psychosocial factors impact IBS is through maladaptive behaviors that impact health outcomes. These behaviors are often adopted in response to idiosyncratic beliefs that patients have about their symptoms. Examples include overestimating the threat value of somatic symptoms (i.e., "catastrophizing") and underestimating one's ability to control or cope with these symptoms (i.e., low "self-efficacy"). Such beliefs often lead patients to avoid situations in which (1) GI symptoms are expected to occur (e.g., eating at a new restaurant) or (2) the consequences of symptoms are expected to be high (e.g., situations where it could be embarrassing or difficult to leave to use the restroom). Avoidance, in turn, serves to reinforce maladaptive cognitions and behaviors ${ }^{16}$. Similar cognitive-behavioral models of symptom responding have been developed in multiple conditions related to IBS, including panic disorder ${ }^{17}$ and chronic pain ${ }^{18}$, suggesting that avoidance maintains symptoms across multiple patient populations.

A fourth mechanism by which psychosocial factors impact IBS is through social learning. Research conducted with both pediatric ${ }^{19-23}$ and adult patient populations ${ }^{24,25}$ indicates that family members' responses prospectively predict patient symptoms and illness behavior. Thus, well-intentioned family members can unintentionally reinforce the acquisition of maladaptive coping strategies - including excessive avoidance of situations associated with threat ${ }^{20,25}$.

\section{THE VALUE OF SCREENING}

As others have $\operatorname{argued}^{14}$, early identification of patients whose symptoms are stress-sensitive or who exhibit maladaptive coping is key to providing more effective treatments. While some patients' symptoms resolve subsequeñt a positive diagnosis and initiation of conventional medical treatment, those with significant psychosocial problems typically benefit from treatment that integrates medical management and behavioral support. Building on the concept of GI "red flags" (i.e., indicators ơf possible underlying organic pathology), rè searchers have coined the term "yellow flags" to refer to psychosocial factors associated with poor response to standard treatment - namely: severe pain, clinically significant anxiet clinically significant depression, trauma histöry, maladaptive coping, and symptom-induced activity interference. Yellow flags can be used to identify patients whose response to pure biomedical treatments is likely to be limited and who will benefit from a multịmodal approach. Additional psychosocial factors associated with clinical outcomes include overall IBS symptom severity, coping self-efficacy, GI-specific anxiety (GSA), and QOL. Vadidated tools for assessing these factors are presented in Table 1.

\section{OPTIMIZING SCREENING EFFORTS}

Clinical gastroenterologist can minimize barriers to screening by integrating assessment into routine clinical practice. Brief, validated screening tools can be added to other clinic forms for completion before the initial consultation. Instructions should include a succinct and clear 
TABLE 1. Screening tools for assessing psychosocial factors related to clinical outcomes in IBS

\begin{tabular}{|c|c|}
\hline Yellow flags & Measure (\# of items) \\
\hline Abdominal pain & $\begin{array}{l}\text { Numeric Rating Scale (1) } \\
\text { Abdominal Pain Index (4) }\end{array}$ \\
\hline Anxiety & $\begin{array}{l}\text { PROMIS Anxiety SF (4) } \\
\text { GAD Scale (7) }\end{array}$ \\
\hline Depression & $\begin{array}{l}\text { PROMIS Depression SF (4) } \\
\text { CES-D (10) } \\
\text { Patient Health Questionnaire (9) }\end{array}$ \\
\hline Trauma & SPAN (if trauma history endorsed; 4) \\
\hline Maladaptive coping & CSQ (abbreviated catastrophizing subscale; 2) \\
\hline Activity interference & $\begin{array}{l}\text { Healthy Days (4) } \\
\text { PROMIS Pain Interference SF (4) }\end{array}$ \\
\hline \multicolumn{2}{|c|}{ Additional psychosocial factors } \\
\hline IBS symptom severity & $\begin{array}{l}\text { IBS Severity Scoring System (5) } \\
\text { Gastrointestinal Rating Scale (13) } \\
\text { UCLA GI Symptom Severity Scale (1) }\end{array}$ \\
\hline Coping self-efficacy & PROMIS - Managing Symptoms SF (4) \\
\hline GI-specific anxiety & Visceral Sensitivity Index (15) \\
\hline Quality of life & IBS - Quality of Life (34) \\
\hline \multicolumn{2}{|c|}{$\begin{array}{l}\text { PROMIS: Patient-Reported Outcomes Measurement Information System; } \\
\text { SF: Short Form; } \\
\text { GAD: Generalized Anxiety Disorder; } \\
\text { CES-D: Center for Epidemiological Studies of Depression; } \\
\text { CSQ: Coping Strategies Questionnaire; } \\
\text { IBS: Irritable bowel syndrome; } \\
\text { GI: Gastrointestinal }\end{array}$} \\
\hline
\end{tabular}

rationale for why the requested information is important to patient care and describe each of the constructs being assessed in a non-stigmatizing way (e.g., "mood" as opposed to "depression"). Results should be scored, reviewed with the patient, and documented in the medical record. To optimize the value of screening measures, readministration at follow-up appointments is helpful.

\section{PHYSICAL HEALTH FACTORS}

\section{Abdominal pain}

Pain is a primary reason that patients seek medical care and can be assessed in a number of ways. A systematic review of instruments to assess abdominal pain in IBS can be found elsewhere ${ }^{27}$. Perhaps the simplest method is the 10-point Numeric Rating Scale (NRS), in which patients rate their abdominal pain sèverity from 1 (no pain) to 10 (the worst pain imaginable). The NRS can be used for repeat:ed end of day or longer (past $24 \mathrm{~h}$; 1 week) recall periods. The typical recall period used in clinical settings is 1 week. The NRS has good construct validity, discriminant validity and clinical responsiveness ${ }^{28}$. A sample of 27 adults with moderate-to-severe IBS was found to have a mean NRS score of 4.5 (standard deviation $[\mathrm{SD}]=2.5)^{28}$, suggesting that scores above 5 may indicate moderate-to-severe IBS. Research on other chronic pain populations 
have suggested that NRS scores of $\leq 5,6-7$, and $\geq 8$ correspond to mild, moderate, and severe pain, respectively ${ }^{29}$.

A limitation of the NRS is that it assesses only a single dimension of pain - that is, intensity. By contrast, the Abdominal Pain Index (API) ${ }^{30}$ is a 4-item measure that assesses the frequency, duration, and intensity of abdominal pain. The API has been validated for use in children, adolescents, and adults ${ }^{30,31}$. In pediatric samples, API score has been shown to significantly predict the presence of an FGID 9 years later $^{30}$. Scoring involves converting items to a 0-5 scale, calculating a mean, and then converting to a 0-4 scale ${ }^{30}$. Among older adolescents with functional abdominal pain, the 90th percentile was 3.3 for males and 3.7 for females ${ }^{30}$; these could make for conservative cut-offs indicating a high likelihood of severe and frequent abdominal pain. While the API is more complicated than the NRS, it has the advantage of assessing multiple dimensions of the pain experience.

The IBS Severity Scoring System (IBS-SSS) ${ }^{32}$ is a 5-item scale that assesses abdominal pain severity, abdominal pain frequency, abdominal distension severity, satisfaction with bowel habits, and life interference using a visual analog scale. Participants are instructed to respond based on how they "currently feel (i.e., over the last 10 days or so)." Each question generates a maximum score of 100; responses are summed for a total possible score of 500 indicating the greatest possible symptom severity. Scores above 300 indicate severe IBS symptoms ${ }^{32}$ that may not respond sufficiently to conventional medical treatments. The Gastrointestinal Rating Scale ${ }^{33,34}$ consists of 13 items that assess problems with satiety, abdominal pain, diarrhea, constipation, and bloating. The response scale ranges from 1 (no discomfort at all) to 7 (very severe discomfort). Item responses are averaged to derive a total score. An intuitive approach to identifying patients with severe symptoms could be to consider total scores above 4 (labeled "moderate discomfort") or 5 ("mod erately severe discomfort") as severe enough to warrant a multimodal approach. Alternatively, a very simple approach to assessing GI symptom severity is the single item 21-poin̆t UCLA GI Symptom Severity Scale ${ }^{35}$ (UCL SSS). The UCLA SSS asks patients to rate their symptoms during the past week on a scale from 0 (no symptoms) to 20 (most intense symptoms imaginable). In a sample of 234 adults with moderate-to-severe IBS, the meañ UCLA SSS score was 11.1 with a SD of $3.9^{36}$. Thus, scores above 11 may indicate IBS symptoms in the "severe" range.

\section{PSYCHOSOCIAL FACTORS}

\section{Anxiety}

Anxiety is the most common psychologicăl complaint among patients with severe IBS 3 . Anxiety can increase attention to somatic symptoms, lead to more frequent health-care utilization, and impact family and social re lationships. Individuals with high levels oิ̀) anxiety are predisposed to a number of unexplained medical symptoms, sometimes rēferred to as "somatization." A number of briêf measures for assessing anxiety are available. The Patient-Reported Outcomes Measurement Information System (PROMIS)* Anxiety Short

* All PROMIS measures can be accessed via http:/ / www. healthmeasures.net/ 
Form $-4^{38}$ assesses several dimensions of anxiety including fear, high focus on anxiety, intense worry, and uneasiness. Item responses range from 1 (never) to 5 (always). Responses are summed to create a total score. A total score of 11 or higher indicates a degree of anxiety greater than $84 \%$ of the general adult population $^{39}$. A child version is available, as are translations to at least nine other languages. The Generalized Anxiety Disorder (GAD)- $7^{40}$ scale is another option that is quick to administer, score, and interpret. GAD is the most common anxiety disorder among IBS patients seeking treatment ${ }^{37}$, which is one advantage of using the GAD-7 in this population. Respondents indicate how often they have been bothered by 7 symptoms during the past 2 weeks on a scale from 0 (not at all) to 4 (nearly every day). Symptoms included are "feeling nervous, anxious or on edge", "not being able to stop or control worrying", "worrying too much about different things", "trouble relaxing", "being so restless that it's hard to sit still", "becoming easily annoyed or irritable" and "feeling afraid as if something might happen." Responses are summed to create a total score. A cut point of 10 or greater has been shown to optimize sensitivity and specificity for identifying GAD. Roughly $89 \%$ of patients with GAD have scores of $>=10$, while $82 \%$ of patients without GAD have scores $<10$. Scores of 15 or greater indicate severe GAD symptoms ${ }^{40}$.

\section{Depression}

The PROMIS Depression Short Form- $4^{38}$ assesses negative mood and cognitions. As with other PROMIS measures, responses are summed to create a total score. A score of 11 or greater indicates that the individual endorses a degree of depression $>84 \%$ of the general population. Another useful measure is the Center for Epidemiological Studies of Depression (CES-D) ${ }^{41,42}$. The 10-item version of this scale assesses mood, feelings of guilit and worthlessness, helplessness and hopê⿳亠丷厂犬lessness, psychomotor retardation, appetițe loss and sleep disturbance. Patients describe the frequency of symptoms over the past 7 days using a scale ranging from 0 (rarely or none of the time) to 3 (most or all of the time). Items are summed to create a total score. A total score $\geq 10$ indicates clinically significañ̆t depression. The Patient Health Questionnaire (PHQ-9) ${ }^{43}$ consists of 9 items that correspond to the diagnostic criteria for a major depressive episode from the Diagnostic and Statisticăl Manual of Mental Disorders (American Psỳchiatric Association, 2000). The PHQ-9 is commonly used because of its simplicity and good psychometric properties. The recall pè riod is the past 2 weeks, and response choices range from 0 (not at all) to 3 (nearly everoy day). Responses are summed to create a totäl score. Total scores $\geq 10$ indicate moderate dẹpression; scores $\geq 20$ indicate severe depres sion. When administering the PHQ-9, it is important that the response to item 9 (which assesses suicidal ideation) is checked before the patient leaves the clinic. If any response other than 0 is given for that item, a risk as sessment is indicated to confirm patieñ safety.

\section{Trauma}

Initial screening for trauma typically consists of a yes/no question ${ }^{44}$ - for example, "Do you have a history of trauma or abuse, including 
physical or sexual abuse?" When a history of trauma is endorsed, further assessment is indicated to determine the presence and severity of current trauma-related symptoms ${ }^{44}$. One assessment tool appropriate for this purpose is the SPAN ${ }^{45}$, a validated 4-item scale derived from the Davidson Trauma Scale ${ }^{46}$. The measure's name is an acronym for the four symptoms it assesses (startle, physically upset by reminders, anger, and numbness). The SPAN has shown good sensitivity and specificity in a range of populations including adults with mixed trauma ${ }^{47}$, U.S. veter$\mathrm{ans}^{48}$, women seeking routine gynecologic care $^{49}$, and women with chronic pelvic pain ${ }^{50}$. Item responses range from 0 to 4 and are summed to create a total score. Total scores of 5 or greater indicate a positive screen for posttraumatic stress disorder and warrant a referral to mental health services.

\section{Maladaptive coping}

Coping is generally defined as an intrapsychic or action-oriented effort to manage a stressor $^{51}$. In the context of chronic pain, coping refers to efforts to tolerate, adjust to, or reduce pain. Interest in pain coping comes from observations that for some individuals, chronic pain results in considerable disability, whereas others adjust fairly well. Research indicates that much of this variation can be attributed to cognitive and behavioral coping strategies $^{52}$. Pain catastrophizing refers to exaggerated negative thinking about the meaning and consequences of pain. Catastrophizing has been linked to greater pain intensity, pain-related disability, emotional distress, and health-care utilization. Catastrophizing can be measured using a 2-item abbreviated version $^{53}$ of the catastrophizing subscale of the Coping Strategies Questionnaire ${ }^{54}$. Participants are asked to indicate how they typically think or feel during an episode of pain. Response choices range from 0 (never think or feel that) to 6 (always think or feel that). Scores are summed to create a total score. Items for the 2-item scale are: "It is terrible and I feel it is never going to get any better" and "I feel I can't stand it anymore." The 2-item scale has good psychometric properties, appears sensitive to treatment and is likely well-suited to busy clinical settings ${ }^{53}$.

\section{Coping self-efficacy}

Coping self-efficacy is defined as one's beliè in one's ability to cope with a specific stressì or $^{55}$. In the context of chronic illness, relevant domains of coping self-efficacy include the patient's confidence in his/her ability to (i) control or reduce physical symptoms ("problem-focused" coping self-efficacy), (2) accepot and adjust to symptoms ("emotion-focused" coping self-efficacy), and/or (3) engage in daìly activities despite symptoms. Self-efficacy expectations determine whether coping will be attempted, the amount of effort that will be expended in the attempt, and how long the individual will persist in the face of obsta cles and aversive experiences ${ }^{56,57}$. Research confirms that coping self-efficacy improves outcomes in patients with chronic health conditions ${ }^{58-60}$ including IBS $^{57}$. However, the goodness-of-fit between the stressor and the type of coping is also important ${ }^{55,61-64}$. While active (problem-focused) approaches are more effective for coping with controllable stressors, emotion-focused coping (e.g., acceptance) is more adaptive for adjusting to uncontrollable 
stressors. Thus, patients with high self-efficacy for both problem- and emotion-focused coping and who are able to apply these strategies flexibly have the best outcomes ${ }^{65}$. Adapted from the pediatric Pain Beliefs Questionnaire ${ }^{66}$, example items for assessing problem- and emotion-focused coping self-efficacy (respectively) might be: "When I have bad pain or GI symptoms, there are ways I can get it to stop" and "I know I can handle it no matter how bad my symptoms are." A validated tool for assessing self-efficacy for engaging in daily activities is the PROMIS-Managing Symptoms Short Form- $4{ }^{67}$, which measures a patient's confidence that he/she can manage symptoms and keep them from interfering with relationships and other aspects of daily life.

\section{GI-specific anxiety (GSA)}

GSA refers to the fear of GI symptoms (e.g., abdominal pain or diarrhea) ${ }^{36}$ due to anticipation of aversive physical, psychological, or social consequences. GSA is thought to heighten central nervous system responsivity toward potentially threatening visceral stimuli or their cues, cause excessive avoidance of activities or situations where GI symptoms are expected to occur, and ultimately increase symptom frequency and intensity ${ }^{36}$. Regarded as a marker of over-responsiveness to visceral sensations, GSA is believed to aggravate symptoms through alterations in autonomic nervous system activity ${ }^{36}$. In a study of 234 patients in which the impact of a variety of physical and psychological variables was investigated, GSA was the most robust predictor of QOL impairment ${ }^{36}$. A validated tool for measuring GSA is the 15-item Visceral Sensitivity Index ${ }^{15}$, which assesses worry, hypervigilance, and heightened focus on GI sensations. Items are rated on a scale from 0 (strongly disagree) to 5 (strongly agree). Responses to negatively worded items are reverse scored, then items are summed to create a total score. In a sample of 100 patients with IBS, the mean total score was $36.5(\mathrm{SD}=18.5)^{15}$. Thus, a total score of 55 or higher may indicate a degree of GSA $>84 \%$ of IBS patients.

\section{Quality of life (QOL)}

Health-related QOL is increasingly recognized as a critical health outcome, particular̆ly for benign medical illnesses like IBS whose impact (and treatment response) is gauged by its daily burden. The IBS-QOL ${ }^{68,69}$ is a $344^{-}$ item measure that assesses perceived impact of IBS on eight QOL domains (dysphoria, interference with activity, body image, health worry, food avoidance, social reaction, sexuâ. dysfunction, and relationships). Each item is scored on a scale from 1 (not at all) to 5 (extremely/a great deal). Items are summed and transformed to a 0-100 scale in which 100 indicates the maximum QOL. The IBS-QOL demonstrates high internal consistency (Cronbach's alpha $=0.95$ ) and reproducibility $(\mathrm{ICC}=0.86)^{69}$. Mean IBS-QOL score in a sample of 156 adults with moderate-to-severe IBS was $65.84(\mathrm{SD}=19.92)^{68}$, suggesting that IBSQOL scores $\leq 65$ may indicate significant QOA impairment due to IBS symptoms.

\section{Activity interference}

A simple approach to assessing both QOL and symptom-related activity interference is the 4-item Healthy Days measure. Developed 
by the Centers for Disease Control and Prevention $^{70}$, the Healthy Days measure asks respondents to indicate the number of days when their (1) physical health and (2) mental health was not good, using a 30-day recall period. Additional items ask respondents to rate their overall health from poor to excellent and to estimate the number of days in which poor physical or mental health kept them from doing their usual activities. The number of physically or mentally unhealthy days over the previous 30 appears less confounded by emotional distress compared to other QOL measures ${ }^{5}$. An alternative tool for brief assessment of activity interference is the PROMIS Pain Interference Short Form - 4, which has been validated in diverse clinical populations ${ }^{71,72}$. If indicated, the word "pain" in this measure could be substituted with "abdominal pain or other GI symptoms" to more fully capture the range of potentially activity interfering symptoms experienced by individuals with IBS.

\section{REFERRING PATIENTS TO A MENTAL HEALTH PROFESSIONAL}

When a yellow flag or other relevant psychosocial problem is identified, the clinician may help to normalize the patient's experience by explaining that such issues are common in individuals with IBS. Next, brief education on the relationship between stress and GI symptoms can be useful. As in any doctor-patient discussion, a motivational interviewing approach ${ }^{73}$ is recommended to determine the patient's openness to learning about the biopsychosocial model. The clinician may also take this opportunity to acknowledge the difficulty that IBS symptoms may be having on the patient's daily life. If the patient expresses interest, a referral to a mental health professional with expertise in chronic pain or FGIDs is warranted. Patients who do not endorse yellow flags but report unresolved GI symptoms may also benefit from such a referral to help them bettêr self-manage symptoms ${ }^{74,75}$. Patients often interpret a mental health referral as an indică tion that the gastroenterologist believes they are "crazy," malingering, or that the symptoms are "all in their head." Thus, the clini cian should explicitly state that she/he be lieves that the patient's symptoms are reấ and that a growing body of rigorous scieñ tific evidence supports the efficacy of behav ioral treatments for improving GI symptoms emotional well-being, and daily functioning in IBS $^{76-79}$. If appropriate, the physician may emphasize that while behavioral treatment may not eliminate GI symptoms, psychồtherapy is useful for learning strategies to cope with stress - including the stress of chronic illness such as IBS. Thus, therapiès such as cognitive behavior therapy (CBT) are highly effective for helping patients reduce the negative impact of symptoms on their lives $^{79}$. Skeptical patients may be more likely to engage when behavioral treatment is prèsented as a complementary form of chronic disease management that has been applied successfully to multiple other "real" medicăl problems with no simple cure (e.g., hyper tension, diabetes, and arthritis). Characteristics of patients who are likely versus unlike ly to benefit from a mental health referral are presented in Table 2.

A variety of psychological therapies have been developed for IBS, and multiple meta-analyses support their efficacy ${ }^{77-79}$. The 
majority of research has been conducted on CBT, which aims to teach patients practical cognitive and behavioral techniques for managing IBS symptoms and related distress. A recent meta-analysis found no significant difference in the efficacy of three major therapeutic modalities (CBT, hypnosis, and relaxation) for reducing GI symptoms ${ }^{78}$. However, CBT appears more effective than other psychological modalities at improving daily functioning ${ }^{79}$. The largest improvements in both GI symptoms and functioning were observed for a CBT intervention that emphasized systematic exposure to IBS symptoms ${ }^{80}$. It is important for gastroenterologists to identify experienced local mental health professionals and to develop relationships with these professionals to facilitate an integrated treatment approach that optimizes outcomes.

\section{BARRIERS TO SCREENING}

Several barriers to routine screening for psychosocial factors in IBS may present themselves. Clinicians may lack familiarity with screening tools, believe that screening is overly time-consuming or expensive, be uncertain of how to treat someone with high

TABLE 2. Positive and negative indicators for a mental health referral

\begin{tabular}{|l|l|}
\hline $\begin{array}{l}\text { Referral advised if the } \\
\text { patient }\end{array}$ & $\begin{array}{l}\text { Referral not advised if } \\
\text { the patient }\end{array}$ \\
\hline $\begin{array}{l}\text { Recognizes a relationship } \\
\text { between stress and GI symptoms }\end{array}$ & $\begin{array}{l}\text { Has strong disease conviction } \\
\text { and commitment to finding a } \\
\text { medical "fix" }\end{array}$ \\
\hline $\begin{array}{l}\text { Has a preference for non-drug } \\
\text { treatment }\end{array}$ & $\begin{array}{l}\text { Does not believe in the } \\
\text { therapeutic potential of } \\
\text { behavioral treatments }\end{array}$ \\
\hline $\begin{array}{l}\text { Is motivated to assume an active } \\
\text { role in treatment }\end{array}$ & $\begin{array}{l}\text { Is not motivated to assume an } \\
\text { active role in treatment }\end{array}$ \\
\hline Gl: Gastrointestinal &
\end{tabular}

scores, or lack confidence that screening will positively inform treatment. The later may stem from difficulty in broaching psychologically sensitive topics or from not knowing where to send patients when a referral is indicated. Furthermore, clinicians may fearr that personal questions or a mental health referral would be necessarily offensive, embarrassing, or open a "can of worms" thằt they are ill prepared to address. Some clingi cians may lack confidence that the patient will comply with a recommendation based on screening. These factors should be weighed against the potential benefits of screening to improve efficiency and efficacy of patieñt care. In our experience, patients typically apo preciate the opportunity to share psychoso cial aspects of their illness experience, provided the clinician conveys confidence thă their symptoms are "real" and actionablè. Acknowledgment of the frustration and daisly burden of IBS can go a long way i⿳亠幺幺. strengthening therapeutic alliance, treatmeñ compliance, and outcomes.

\section{CONCLUSION}

Psychosocial issues play an important role in the expression of IBS - particularly among those patients who seek treatment in tertiary care settings. Gastroenterologists can inprove efficiency and quality of care through routine screening for psychosocial factofs that predict clinical outcomes. Psychosociāal "yellow flags" can identify patients who are likely to need a multimodal approach, thereby decreasing the disappointment that arises when medical treatments fall short of therapeutic objectives. Once such individuals are identified, appropriate referrals can be made 


\section{to professionals with expertise in behavioral treatment for chronic pain or FGIDs. Even in cases where a referral is not indicated, such routine screening can facilitate discussion of sensitive subjects, provide valuable insight into the complexity of a patient's symptom profile, and inform clinical decision-making to ultimately improve outcomes.}

\section{REFERENCES}

1. Canavan C, West J, Card T. The epidemiology of irritable bowel syndrome. Clin Epidemiol. 2014;6:71-80.

2. Inadomi JM, Fennerty MB, Bjorkman D. Systematic review: The economic impact of irritable bowel syndrome. Aliment Pharmacol Ther. 2003;18:671-82.

3. Hungin AP, Chang L, Locke GR, Dennis EH, Barghout V. Irritable bowel syndrome in the United States: Prevalence, symptom patterns and impact. Aliment Pharmacol Ther. 2005;21:1365-75.

4. Pace F, Molteni P, Bollani S, et al. Inflammatory bowel disease versus irritable bowel syndrome: A hospital-based, case-control study of disease impact on quality of life. Scand J Gastroenterol. 2003;38:1031-8.

5. Lackner JM, Gudleski GD, Zack MM, et al. Measuring health-related quality of life in patients with irritable bowel syndrome: Can less be more? Psychosom Med. 2006;68:312-20.

6. Mayer EA, Labus JS, Tillisch K, Cole SW, Baldi P. Towards a systems view of IBS. Nat Rev Gastroenterol Hepatol. 2015;12:592-605.

7. Lackner JM. The Role of Psychosocial Factors in Functional Gastrointestinal Disorders Functional and GI Motility Disorders. Vol. 33. New York, USA: Karger Publishers; 2014. p. 104-16.

8. Talley NJ, Fett SL, Zinsmeister AR, Melton LJ 3rd. Gastrointestinal tract symptoms and self-reported abuse: A population-based study. Gastroenterology. 1994;107:1040-9.

9. Bradford K, Shih W, Videlock EJ, et al. Association between early adverse life events and irritable bowel syndrome. Clin Gastroenterol Hepatol. 2012;10:385-90.

10. Talley NJ, Fett SL, Zinsmeister AR. Self-reported abuse and gastrointestinal disease in outpatients: Association with irritable bowel-type symptoms. Am J Gastroenterol. 1995;90:366-71.

11. Drossman DA, Li Z, Leserman J, Toomey TC, Hu YJ. Health status by gastrointestinal diagnosis and abuse history. Gastroenterology. 1996;110:999-1007.

12. Leserman J, Li Z, Drossman DA, Hu YJ. Selected symptoms associated with sexual and physical abuse history among female patients with gastrointestinal disorders: The impact on subsequent health care visits. Psychol Med. 1998;28:417-25.

13. Drossman DA. Abuse, trauma, and GI illness: Is there a link? Am J Gastroenterol. 2011;106:14-25.

14. Chang L. The role of stress on physiological responses and clinical symptoms in irritable bowel syndrome. Gastroenterology. 2011;140:761.

15. Labus JS, Bolus R, Chang L, et al. The visceral sensitivity index: Development and validation of a gastrointestinal symptom-specific anxiety scale. Aliment Pharmacol Ther. 2004;20:89-97.

16. Ljótsson B, Hesser H, Andersson E, et al. Provoking symptoms to relieve symptoms: A randomized controlled dismantling study of exposure therapy in irritable bowel syndrome. Behav Res Ther. 2014;55:27-39.

17. Reiss S, Peterson RA, Gursky DM, McNally RJ. Anxiety sensitivity, anxiety frequency and the prediction of fearfulness. Behav Res Ther. 1986;24:1-8.
18. Crombez G, Eccleston C, Damme SV, Vlaeyen JW, Karoly P. Fear-avoidance model of chronic pain: The next generation. Clin J Pain. 2012;28:475-83.

19. Claar RL, Simons LE, Logan DE. Parental response to children's pain: The moderating impact of children's emotional distress on symptoms and disability. Pain. 2008;138:172-9.

20. Walker LS, Williams SE, Smith CA, et al. Parent attention versus distraction: Impact on symptom complaints by children with and without chronic functional abdominal pain. Pain. 2006;122:43-52.

21. Walker LS, Zeman JL. Parental response to child illness behavior. J Pediâtr Psychol. 1992;17:49-71.

22. Slyke DA, Walker LS. Mothers' responses to children's pain. Clin J Pain 2006;22:387-91.

23. Manimala M, Blount $\mathrm{R}, \mathrm{Cohen} \mathrm{L}$. The effects of parental reassurance versu్ distraction on child distress and coping during immunizations. Child Health Care. 2000;29:161-77.

24. Flor H, Knost B, Birhaumer N. The role of operant conditioning in chronic pain: An experimental investigation. Pain. 2002;95:111-8.

25. Romano JM, Turner JA, Friedman LS, et al. Sequential analysis of chronic pain behaviors and spouse responses. J Consult Clin Psychol. 1992;60:777 $=\frac{-82}{7}$

26. Lackner JM, Gudleski GD, Haroon M, et al. Proactive screening for psychorsocial risk factors in moderate to severe patients with irritable bowel syndrome: The predictive validity of the rome III psychosocial alarm questiennaire. Neuroenterology. 2012;1:1-7.

27. Mujagic Z, Keszthelyi D, Aziz Q, et al. Systematic review: Instruments to assess abdominal pain in irritable bowel syndrome. Aliment Pharmacol Ther. 2015;42:1064-81.

28. Spiegel B, Bolus R, Harris LA, et al. Measuring irritable bowel syndrome patient-reported outcomes with an abdominal pain numeric rating scale. Aliment Pharmacol Ther. 2009;30:1159-70.

29. Boonstra AM, Stewart RE, Köke AJ, et al. Cut-off points for mild, moderate and severe pain on the numeric rating scale for pain in patients with chronic musculoskeletal pain: Variability and influence of sex and catastrophizing. Front Psychol. 2016;7:1466.

30. Laird KT, Sherman AL, Smith CA, Walker LS. Validation of the abdominal pain index using a revised scoring method. J Pediatr Psychöl. 2015;40:512-25.

31. Walker LS, Smith CA, Garber J, Slyke DA. Development and validationof the pain response inventory for children. Psychol Assess. 1997;9:392-405.

32. Francis C, Morris J, Whorwell P. The irritable bowel severity scoring syes tem: A simple method of monitoring irritable bowel syndrome and $\overline{\mathrm{at}}$ progress. Aliment Pharmacol Ther. 1997;11:395-402.

33. Svedlund J, Sjödin I, Dotevall G. GSRS--a clinical rating scale for gastrointestinal symptoms in patients with irritable bowel syndrome and peptic ulcer disease. Dig Dis Sci. 1988;33:129-34.

34. Wiklund IK, Fullerton S, Hawkey CJ, et al. An irritable bowel sym drome-specific symptom questionnaire: Development and validation Scand J Gastroenterol. 2003;38:947-54.

35. Spiegel B, Strickland A, Naliboff BD, Mayer EA, Chang L. Predictors of patient-assessed illness severity in irritable bowel syndrome. Am J Gastroenterol. 2008;103:2536-43.

36. Lackner JM, Gudleski GD, Ma CX, et al. Fear of GI symptoms has ă important impact on quality of life in patients with moderate-to-severe $\overline{I B S}$. Am J Gastroenterol. 2014;109:1815-23.

37. Lackner JM, Ma CX, Keefer L, et al. Type, rather than number, of mentea and physical comorbidities increases the severity of symptoms in patients with irritable bowel syndrome. Clin Gastroenterol Hepatol. 2013;11:1147-57.

38. Pilkonis PA, Choi SW, Reise SP, et al. Item banks for measuring emotional distress from the patient-reported outcomes measurement information system (PROMIS®): Depression, anxiety, and anger. Assessment. 2011;18:263-83.

39. PROMIS. Patient-Reported Outcomes Measurement Information System; 2015. Available from: https://www.assessmentcenter.net/documents/ PROMISAnxietyScoringManual.pdf. [Last retrieved on 2017 Sep 30].

40. Spitzer RL, Kroenke K, Williams JB, Löwe B. A brief measure for assessing generalized anxiety disorder: The GAD-7. Arch Intern Med. 2006;166:1092-7. 
41. Andresen EM, Malmgren JA, Carter WB, Patrick DL. Screening for depression in well older adults: Evaluation of a short form of the CES-D (Center for Epidemiologic Studies Depression Scale). Am J Prev Med. 1994;10:77-84.

42. Irwin M, Artin KH, Oxman MN. Screening for depression in the older adult: Criterion validity of the 10-item center for epidemiological studies depression scale (CES-D). Arch Intern Med. 1999;159:1701-4.

43. Spitzer RL, Kroenke K, Williams JB. Validation and utility of a self-report version of PRIME-MD: The PHQ primary care study. Primary care evaluation of mental disorders. Patient health questionnaire. JAMA. 1999;282: 1737-44.

44. Center for Substance Abuse Treatment. Screening and Assessment. In: Substance Abuse and Mental Health Services Administration (US). Trauma-Informed Care in Behavioral Health Services. Series 57. Ch. 4. Rockville, MD: Treatment Improvement Protocol (TIP); 2014.

45. Meltzer-Brody S, Churchill E, Davidson JR. Derivation of the SPAN, a brief diagnostic screening test for post-traumatic stress disorder. Psychiatry Res. 1999;88:63-70.

46. Davidson JR, Book SW, Colket JT, et al. Assessment of a new self-rating scale for post-traumatic stress disorder. Psychol Med. 1997;27:153-60.

47. Brewin CR. Systematic review of screening instruments for adults at risk of PTSD. J Trauma Stress. 2005;18:53-62.

48. Calhoun PS, McDonald SD, Guerra VS, et al. Clinical utility of the primary Care-PTSD screen among US veterans who served since September 11, 2001. Psychiatry Res. 2010;178:330-5.

49. Meltzer-Brody S, Hartmann K, Miller WC, et al. A brief screening instrument to detect posttraumatic stress disorder in outpatient gynecology. Obstet Gynecol. 2004;104:770-6.

50. Meltzer-Brody S, Leserman J, Zolnoun D, et al. Trauma and posttraumatic stress disorder in women with chronic pelvic pain. Obstet Gynecol. 2007;109:902-8.

51. Lazarus RS, Launier R. Stress-related transactions between person and environment. Perspectives in Interactional Psychology. New York: Springer. 1978. p. 287-327.

52. Robinson ME, Riley JL 3rd, Myers CD, et al. The coping strategies questionnaire: A large sample, item level factor analysis. Clin J Pain. 1997;13:43-9.

53. Jensen MP, Keefe FJ, Lefebvre JC, Romano JM, Turner JA. One-and two-item measures of pain beliefs and coping strategies. Pain. 2003;104:453-69.

54. Rosenstiel AK, Keefe FJ. The use of coping strategies in chronic low back pain patients: Relationship to patient characteristics and current adjustment. Pain. 1983;17:33-44.

55. Lazarus RS, Folkman S. Stress, Appraisal, and Coping. New York: Springer Publishing Company; 1984.

56. Bandura A. Social Learning Theory. Englewood Cliffs, NJ: Prentice-Hall; 1977.

57. Drossman DA, Leserman J, Li Z, et al. Effects of coping on health outcome among women with gastrointestinal disorders. Psychosom Med. 2000;62:309-17.

58. Lorig K, Chastain RL, Ung E, Shoor S, Holman HR. Development and evaluation of a scale to measure perceived self-efficacy in people with arthritis. Arthritis Rheum. 1989;32:37-44

59. Bandura A. Self-efficacy mechanism in psychobiologic functioning. Self-efficacy: Thought Control of Action. Vol. 2. Washington, DC: Erlbaum; 1992.

60. Buckelew SP, Parker JC, Keefe FJ, et al. Self-efficacy and pain behavior among subjects with fibromyalgia. Pain. 1994;59:377-84.

61. Roubinov DS, Turner AP, Williams RM. Coping among individuals with multiple sclerosis: Evaluating a goodness-of-fit model. Rehabil Psychol. 2015;60:162.
62. Park CL, Folkman S, Bostrom A. Appraisals of controllability and coping in caregivers and HIV+ men: Testing the goodness-of-fit hypothesis. J Consult Clin Psychol. 2001;69:481.

63. Park CL, Sacco SJ, Edmondson D. Expanding coping goodness-of-fit: Religious coping, health locus of control, and depressed affect in heart failure patients. Anxiety Stress Coping. 2012;25:137-53.

64. Forsythe CJ, Compas BE. Interaction of cognitive appraisals of stressfu events and coping: Testing the goodness of fit hypothesis. Cognit Ther Res. 1987;11:473-85.

65. Radziwon C, Lackner JM. Coping flexibility, GI symptoms, and functiona GI disorders: How translational behavioral medicine research can inform GI practice. Clin Transl Gastroenterol. 2015;6:e117.

66. Stone AL, Walker LS, Laird KT, et al. Pediatric pain beliefs questionnaire Psychometric properties of the short form. J Pain. 2016;17:1036-44.

67. Gruber-Baldini AL, Velozo C, Romero S, Shulman LM. Validation of the PROMIS $®$ measures of self-efficacy for managing chronic conditions. Qual Life Res. 2017;26:1915-24.

68. Drossman DA, Patrick DL, Whitehead WE, et al. Further validation of the IBS-QOL: A disease-specific quality-of-life questionnaire. Am J Gastroenterol. 2000;95:999-1007

69. Patrick DL, Drossman DA, Frederick IO, DiCesare J, Puder KL. Qualityð life in persons with irritable bowel syndrome: Development and validation of a new measure. Dig Dis Sci. 1998;43:400-11.

70. Centers for Disease. Measuring Healthy Days: Population Assessment ${ }^{\circ}$ Health-Related Quality of Life. Atlanta, GA: Centers for Disease Control and Prevention; 2000.

71. Askew RL, Cook KF, Revicki DA, Cella D, Amtmann D. Clinical validity of PROMIS $®$ pain interference and pain behavior in diverse clinical populations. J Clin Epidemiol. 2016;73:103.

72. Amtmann D, Cook KF, Jensen MP, et al. Development of a PROMIS item bank to measure pain interference. Pain. 2010;150:173-82.

73. Rollnick S, Miller WR, Butler CC. Motivational Interviewing in Health Care Helping Patients Change Behavior. New York: Taylor \& Francis; 2008.

74. Lackner JM, Jaccard J, Krasner SS, et al. How does cognitive behavior therapy for irritable bowel syndrome work? A mediational analysis of randomized clinical trial. Gastroenterology. 2007;133:433-44.

75. Drossman DA, Camilleri M, Mayer EA, Whitehead WE. AGA technica review on irritable bowel syndrome. Gastroenterology. 2002;123:2108-31.

76. Lackner JM, Mesmer C, Morley S, Dowzer C, Hamilton S. Systematic reviề and meta-analysis of randomized controlled trials of psychological treat ments for irritable bowel syndrome. Gastroenterology. 2003;124:A529.

77. Ford AC, Quigley EM, Lacy BE, et al. Effect of antidepressants and psy chological therapies, including hypnotherapy, in irritable bowel sy̆ndrome: Systematic review and meta-analysis. Am J Gastroenterōol 2014;109:1350-65.

78. Laird KT, Tanner-Smith EE, Russell AC, Hollon SD, Walker LS. Short- anid long- term efficacy of psychological therapies for irritable bowel syndrome: A systematic review and meta-analysis. Clin Gastroenterol Hepatôl. 2016;14:937-47.

79. Laird KT, Tanner-Smith EE, Russell AC, Hollon SD, Walker LS. Compara tive efficacy of psychological therapies for improving mental health añ. daily functioning in irritable bowel syndrome: A systematic review $\overline{\text { and }}$ meta-analysis. Clin Psychol Rev. 2017;51:142-52.

80. Ljotsson B, Andersson G, Andersson E, et al. Acceptability, effectivenèss, and cost-effectiveness of internet-based exposure treatment for irritabje bowel syndrome in a clinical sample: A randomized controlled trial. BMC Gastroenterol. 2011;11:110. 